\title{
Adsorption isotherm modeling for methylene blue removal onto magnetic kaolinite clay: a comparison of two-parameter isotherms
}

\author{
Victor O. Shikuku ${ }^{1} \cdot$ Trilochan Mishra ${ }^{2}$
}

Received: 23 January 2020 / Accepted: 27 May 2021 / Published online: 2 June 2021

(c) The Author(s) 2021

\begin{abstract}
In this work, kaolinite clay was modified with magnetic magnetite nanoparticles $\left(\mathrm{Fe}_{3} \mathrm{O}_{4} @ \mathrm{MC}\right)$ by co-precipitation with ferrous and ferric ions as iron precursors to ameliorate its textural and adsorption capacity for methylene blue (MB) dye uptake from synthetic wastewater at low concentrations. The adsorbents were characterized using XRD, BET surface area analysis, VSM, SEM and HRTEM. The BET surface area after chemical treatment increased from 14.616 to $26.913 \mathrm{~m}^{2} \mathrm{~g}^{-1}$. The saturation magnetization of $\mathrm{Fe}_{3} \mathrm{O}_{4} @ \mathrm{MC}$ was $6.22 \mathrm{emu} \mathrm{g}^{-1}$ and the exhausted adsorbent recoverable by a simple magnet. Adsorption data were modeled using six nonlinear two-parameter isotherm equations, namely Freundlich, Temkin, FowlerGuggenheim, Elovich, Flory-Huggins and Langmuir model, and the best-fitting model arrived at using three mathematical error functions. MB adsorption onto unmodified clay was best described by the Fowler-Guggenheim isotherm, whereas $\mathrm{MB}$ adsorption onto $\mathrm{Fe}_{3} \mathrm{O}_{4} @ \mathrm{MC}$ was best described by the Freundlich model. Increase in BET surface area increased the theoretical and experimental maximum adsorption capacity
\end{abstract}

Keywords Kaolinite $\cdot$ Methylene blue $\cdot$ Magnetite $\cdot$ Adsorption isotherms

\section{Introduction}

Industrial processes are one of the leading point sources of dye-containing effluents released into the environment. Specifically, the textile industries are major emitters of large volumes of colored wastewater (Mohantry et al. 2006). Besides, the increasing need for textile production and the corresponding increase in their production are major factors leading to dye-bearing effluents becoming among the prominent point sources of surface-water contamination in recent years (Ogugbue and Sawidis 2011).

The dye contaminated wastewater has been associated with several health disorders (Yasemin and Haluk 2006). Most of the synthetic dyes are carcinogenic and mutagenic and their occurrence in aquatic environment raises

Victor O. Shikuku

odhiambo_shik@yahoo.com

1 Department of Physical Sciences, Kaimosi Friends University College, P.O. Box 385-50309, Kaimosi, Kenya

2 AMP Division, CSIR-National Metallurgical Laboratory, Jamshedpur 831007, India serious health concerns (Ozer et al. 2007). Methylene blue (MB) dye, a cationic dye, has been linked with side effects expressed as nausea, vomiting and diarrhea (El-Sharkaway et al. 2007). The techniques for discolorations of effluents have been categorized into three classes: chemical, physical and biological. All of the aforementioned techniques have inherent limitations and strengths. Among the dye sequestration techniques, adsorption onto activated carbon remains the widely used method for discoloration of aqueous solutions (Markovska et al. 2001). However, activated carbon is not only expensive, but also demanding to regenerate, necessitating the search for alternative low-cost, naturally available and sustainable adsorbents such as clays (Li et al. 2010; Shikuku et al. 2019).

Karim et al. (2017) reported effective removal of Basic Red 46 (BR46), methylene blue (MB) and malachite green (GM) cationic dyes onto a Moroccan clay. The removal of methyl orange (MO) by an activated Algerian clay was also described by Bendahoet al. (2017). Noteworthy, the recent review by Adeyemoet al. (2017) scrutinized the unresolved aspects of the adsorptive properties of the clays and the enhanced adsorption capacities of chemically tuned clay minerals. The review not only established that the 
modification of raw clays is essential in the development of highly efficient clay-based sorbents for the uptake of dyes from aqueous media but also the paucity of data of performance of clays at low dye concentrations. Another challenging aspect of the adsorption process is to separate the contaminant-laden adsorbent after the adsorption process. In this regard, magnetic adsorbents have been studied with different compositions (Cottet et al. 2014; Shah et al. 2018; Zou et al. 2018) for decontamination of water. However, in these studies, mostly bentonites and montmorillonites are used to prepare composites and used to remove dyes and toxic metals. However, we tried to explore the local kaolinite clay of Kenya, a well-known naturally occurring low-cost clay, as effective adsorbents toward MB dye. Consequently, the objective of this study is to examine the potential of magnetite-modified kaolinite clay for MB uptake and to investigate the adsorbate-adsorbent interactions by nonlinear isotherm modeling approach. Incorporation of magnetite is expected to ameliorate the surface characteristics of the clay and ease the recovery of the dye-bearing adsorbent by an external magnetic field.

\section{Materials and methods}

\section{Synthesis of adsorbent}

The kaolinite clay used in this work was supplied by the Department of Chemistry, Maseno University-Kenya. The chemical composition of the as supplied kaolinite clay mineral was 53.51, 43.59, 2.37, 1.71, 0.84 and $0.36 \mathrm{wt} \%$ for $\mathrm{SiO}_{2}, \mathrm{Al}_{2} \mathrm{O}_{3}, \mathrm{Fe}_{2} \mathrm{O}_{3}, \mathrm{TiO}_{2}, \mathrm{CuO}$ and $\mathrm{K}_{2} \mathrm{O}$, respectively (Otieno et al. 2019), and the mineralogical phases confirmed by XRD analysis.

Synthesis of magnetite/clay composite was done by suspending $2.0 \mathrm{~g}$ of clay in $50 \mathrm{~mL}$ of deionized water and mixed with $100 \mathrm{~mL}$ of a solution containing $\mathrm{Fe}^{3+}(0.228 \mathrm{M})$ and $\mathrm{Fe}^{2+}(0.114 \mathrm{M})$ ions $(\mathrm{pH} \sim 1.40)$ with $2: 1 \mathrm{M}$ ratio. A subsequent amount alkali $(0.5 \mathrm{M} \mathrm{NaOH})$ was added dropwise until the $\mathrm{pH}$ was 9.5-10 for complete precipitation of $\mathrm{Fe}_{3} \mathrm{O}_{4}$ (Cottet et al. 2014). The suspension was ultrasonically agitated for $30 \mathrm{~min}$. The precipitates were allowed to settle, filtered then washed severally with deionized water, then dried in an oven at $100{ }^{\circ} \mathrm{C}$. The dried samples were stored in sealed plastic vials for further characterization.

\section{Adsorbent characterization}

The crystalline phases of the as-received clay material were identified using an X-ray Brucker diffractometer (D8 Discovery, US) with copper radiation $\left(K_{\alpha}=1.5406\right)$. The BET-specific surface areas of the adsorbents (unmodified and treated clay) were obtained by the liquid $\mathrm{N}_{2}$ adsorption-desorption method. The magnetic measurements of the iron modified clay were determined by vibrating-sample magnetometer (VSM), while the surface morphology was inspected using scanning electron microscopy (SEM) (Nova Nano SEM, FEI 430) and high-resolution transmission electron microscopy (HRTEM JEOL JEM-1230 with accelerating voltage of $120 \mathrm{kV}$ ).

\section{Adsorption experiments}

For batch experiments, $0.05 \mathrm{~g}$ of each adsorbent was added to $50 \mathrm{~mL}$ solutions of low concentrations of methyl blue (MB) dye, in the range of 1 to $5 \mathrm{mg} \mathrm{L}^{-1}$, obtained by dissolution of required MB in double-distilled water. The contents of the sealed bottles were allowed to interact for $3 \mathrm{~h}$ at room temperature $\left(27^{\circ} \mathrm{C}\right)$. Determination of the residual MB concentrations in the aqueous phase was determined using a UV-Vis spectrometer at $664 \mathrm{~nm}$. The amount of MB in the solid phase $\left(q_{\mathrm{e}}\right)$ was worked out using the equation:

$q_{\mathrm{e}}=\frac{\left(C_{\mathrm{i}}-C_{\mathrm{e}}\right) V}{m}$

The isothermal data were tested against six nonlinear adsorption models, namely Langmuir, Freundlich, Temkin, Elovich, Fowler-Guggenheim and Flory-Huggins models, were tested to provide insight on the adsorbate-adsorbent interactions, and the best-fitting model determined using three error functions, viz. average relative error (ARE), the sum of absolute errors (EABS) and Chi-square $\left(\chi^{2}\right)$. The nonlinear regression was performed by minimizing the values of the regression sum of squares (RSS) given by:

$\mathrm{RSS}=\sum_{1}^{N}\left(q_{\mathrm{e}, \text { experimental }}-q_{\mathrm{e} \text {,predicted }}\right)^{2}$

\section{Results and discussion}

\section{XRD analysis}

The magnetically responsive clay adsorbent material was synthesized from clay without any pretreatments. Figure 1 shows the XRD pattern for the clay material. The diffraction peaks at $2 \theta=14.20^{\circ}, 23.40^{\circ}, 28.82^{\circ}, 40.60^{\circ}, 81.15^{\circ}, 88.00^{\circ}$ correspond to the kaolinite phase (01-075-0938), while the peaks at $2 \theta=30.92^{\circ}, 58.85^{\circ}$ and $75.92^{\circ}$ depict the presence of quartz (04-008-4821).

\section{BET surface area characteristics}

The textural characteristics of the adsorbents are presented in Table 1. It can be seen that precipitation of magnetite particles into the clay matrix increased the 


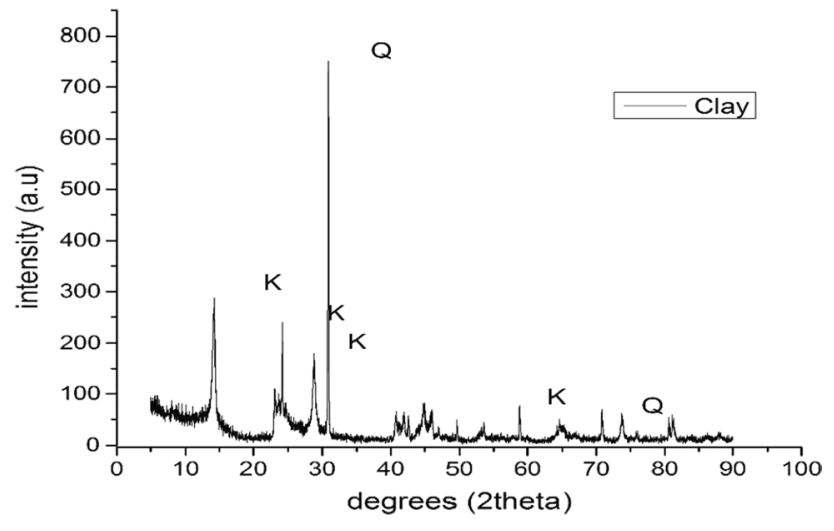

Fig. 1 XRD pattern for clay

Brunauer-Emmett-Teller (BET) specific surface area of the composite clay $\left(\mathrm{Fe}_{3} \mathrm{O}_{4} @ \mathrm{MC}\right)$ relative to the untreated clay.

The increase in the BET surface area of $\mathrm{Fe}_{3} \mathrm{O}_{4} @ \mathrm{MC}$ is expected to be beneficial for adsorption. The observed increase in specific surface area with the addition of iron oxide particles is probably due to partial intercalation of iron oxide in the clay layers (Louhichi et al. 2016), thus creating new interlayer porosity. Boukhemkhem and Rida (2017) reported BET surface area of $14 \mathrm{~m}^{2} \mathrm{~g}^{-1}$ for kaolinite from Algeria. Cottet et al. (2014) reported increased BET surface area for montmorillonite clay after incorporation of magnetite $\left(\mathrm{Fe}_{3} \mathrm{O}_{4}\right)$ by co-precipitation as in the present work. However, intercalation in kaolinite is difficult in comparison to montmorillonite, and hence, the increase in surface area is nominal. Increased adsorbent surface areas are expected to exhibit higher adsorption capacities.

\section{Magnetic properties}

The investigation of the magnetic characteristics of the $\mathrm{Fe}_{3} \mathrm{O}_{4} @ \mathrm{MC}$ was performed by the magnetization curve obtained by the VSM analysis. The saturation magnetization of the prepared magnetic particles $\left(\mathrm{Fe}_{3} \mathrm{O}_{4}\right)$ and composite $\left(\mathrm{Fe}_{3} \mathrm{O}_{4} @ \mathrm{MC}\right)$ as shown in Fig. 2 is 66.5 and $6.22 \mathrm{emu} \mathrm{g}^{-1}$, respectively. With the obtained saturation magnetization, the synthesized $\mathrm{Fe}_{3} \mathrm{O}_{4} @ \mathrm{MC}$ was easily recoverable by an external magnetic field, and therefore, the separation of the dye-laden adsorbent from the bulk liquid phase was simple. Hysteresis loop was only observable for the $\mathrm{Fe}_{3} \mathrm{O}_{4}$ curve.

Table 1 Surface areas for the prepared adsorbents

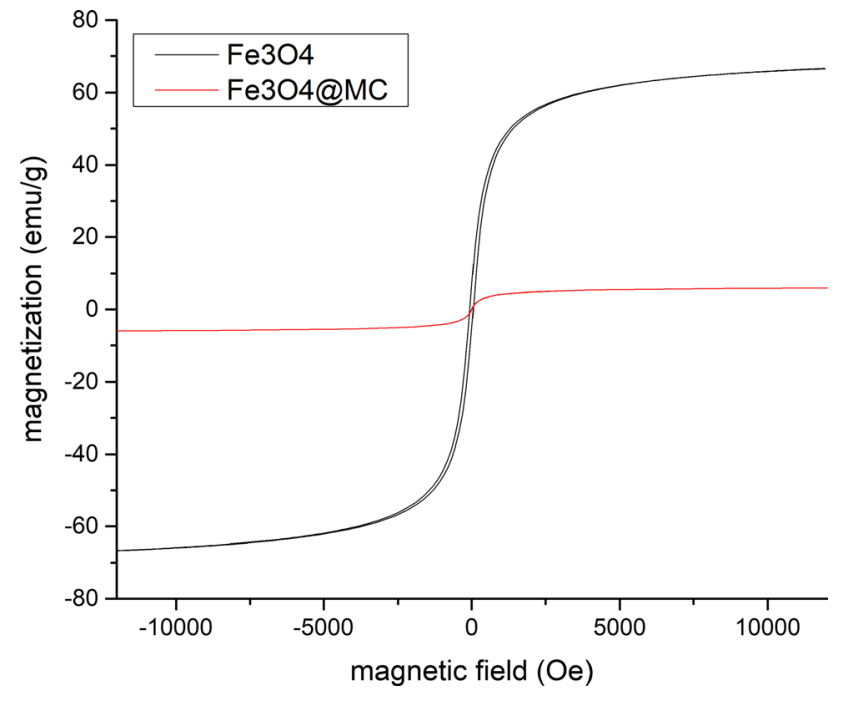

Fig. 2 Magnetization curve for $\mathrm{Fe}_{3} \mathrm{O}_{4}$ and $\mathrm{Fe}_{3} \mathrm{O}_{4} @ \mathrm{MC}$

\section{Surface morphology analysis}

The SEM (Fig. 3a) and HRTEM micrographs of $\mathrm{Fe}_{3} \mathrm{O}_{4} @ \mathrm{MC}$ (Fig. 3b-d) showed the near-spherical $\mathrm{Fe}_{3} \mathrm{O}_{4}$ nanoparticles of 10-20 nm diameter were well dispersed on the surface of the layered clay with little agglomeration. Well crystalline nature of the magnetic particle is noticed in Fig. 3d. The micrographs for $\mathrm{Fe}_{3} \mathrm{O}_{4} @ \mathrm{MC}$ are similar as those reported for precipitation of magnetite $\left(\mathrm{Fe}_{3} \mathrm{O}_{4}\right)$ particles onto montmorillonite clay surface (Cottet et al. 2014). Most of the magnetic particles are anchored on the surface only. Uniform dispersion of the magnetic particles on the clay will help in the proper magnetic separation of the materials after every batch of the adsorption.

\section{Adsorption isotherm}

To understand the adsorbent-adsorbate interactions, the adsorption data were examined using six two-parameter isotherm equations, namely Langmuir, Freundlich, Temkin, Elovich, Fowler-Guggenheim and Flory-Huggins models. Linear regression of adsorption isotherms has been reported to be unsuitable for the determination of isotherm parameters leading to erroneous conclusions (Shikuku et al. 2018; Jemutai-Kimosop et al. 2019). Additionally, studies have shown that the sole use of the coefficient of determination, $R^{2}$, for the determination of best-fitting kinetic and adsorption models is insufficient (Zheng et al. 2019). In the present work, nonlinear regression approach was used to calculate the isotherm parameters and the best-fitting isotherm arrived at using three mathematical error functions; the average relative error (ARE), the sum of absolute errors (EABS) and nonlinear Chi-square $\left(\chi^{2}\right)$ shown in Table 2. The nonlinear

\begin{tabular}{ll}
\hline Adsorbent & $\begin{array}{l}\text { BET surface } \\
\text { area }\left(\mathrm{m}^{2} \mathrm{~g}^{-1}\right)\end{array}$ \\
\hline Untreated clay & 14.616 \\
$\mathrm{Fe}_{3} \mathrm{O}_{4} @ \mathrm{MC}$ & 26.913 \\
\hline
\end{tabular}


Fig. 3 a SEM and b-d HRTEM images of $\mathrm{Fe}_{3} \mathrm{O}_{4} @ \mathrm{MC}$ at different enlargements
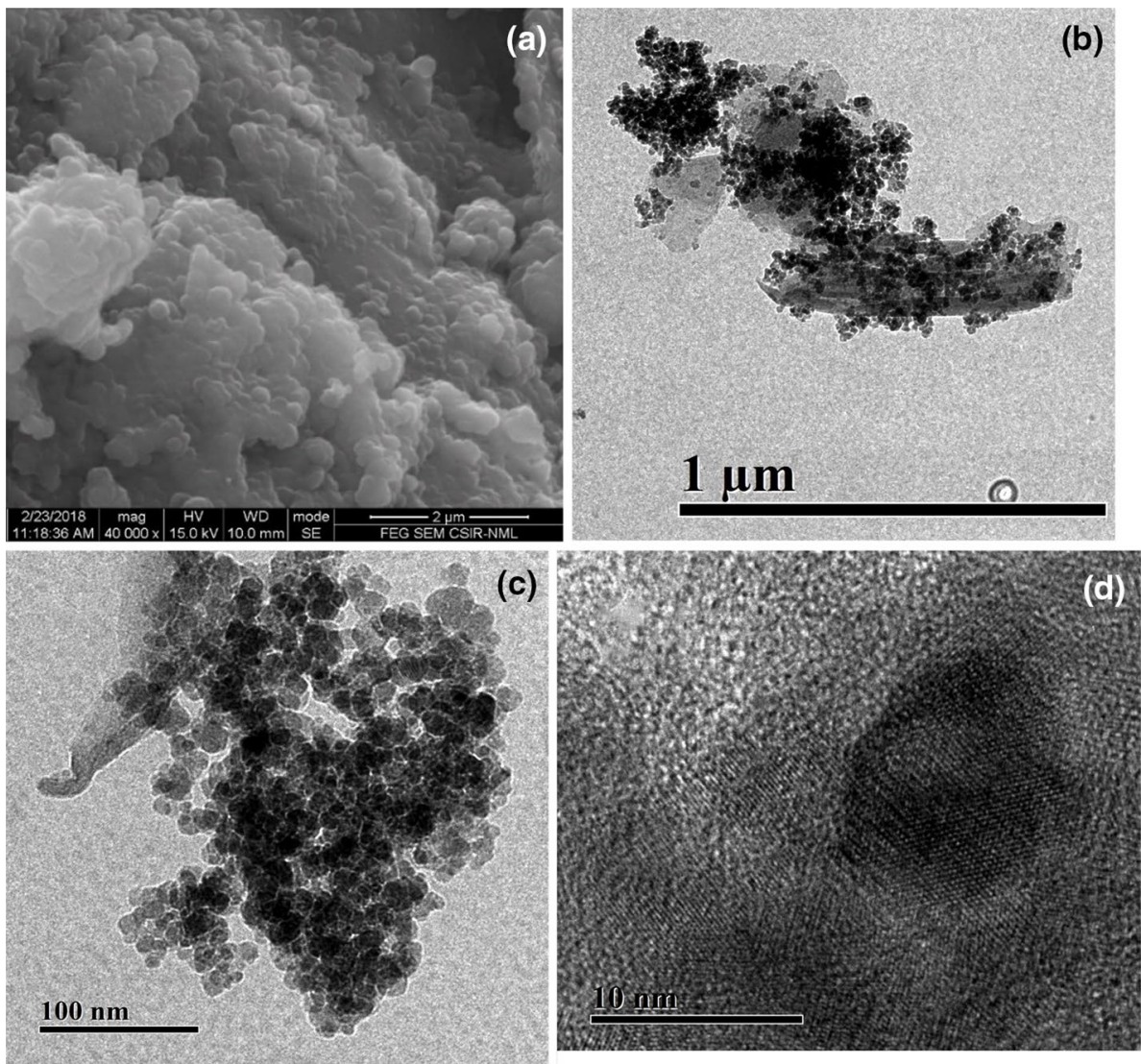

Table 2 Mathematical error functions

\begin{tabular}{ll}
\hline Error function & Equation \\
\hline Nonlinear Chi-square $\left(\chi^{2}\right)$ & $\sum_{i=1}^{n} \frac{\left(q_{\mathrm{e}(\mathrm{cal})}-q_{\mathrm{e}(\exp )}\right)^{2}}{q_{\mathrm{e}(\exp )}}$ \\
The sum of absolute errors (EABS) & $\sum_{i=1}^{n}\left|\left(q_{\mathrm{e}(\mathrm{cal})}-q_{\mathrm{e}(\exp )}\right)\right|$ \\
Average relative error (ARE) & $\frac{100}{n} \sum_{i=1}^{n} \frac{\left(q_{\mathrm{e}(\exp )}-q_{\mathrm{e}(\mathrm{cal})}\right)}{q_{\mathrm{e}(\exp )}}$
\end{tabular}

$q_{\mathrm{e}(\mathrm{exp})}$ are experimental values, $q_{\mathrm{e}(\mathrm{cal})}$ are model calculated values, $n$ is the number of data points, and $p$ is the number of parameters in the isotherm model isotherm model parameter values for adsorption of $\mathrm{MB}$ by the unmodified clay (UC) and the $\mathrm{Fe}_{3} \mathrm{O}_{4} @ \mathrm{MC}$ are listed in Tables 3 and 4, respectively.

\section{Langmuir isotherm}

Langmuir (1916) isotherm equation postulates a monolayer adsorption of adsorbate onto a homogeneous adsorbing surface characterized by energetically identical binding sites. The model further assumes no lateral interactions between adsorbed molecules. The Langmuir equation is expressed as:

$q_{\mathrm{e}}=\frac{Q_{0} K_{\mathrm{L}} C_{\mathrm{e}}}{1+K_{\mathrm{L}} C_{\mathrm{e}}}$

Table 3 Nonlinear isotherm model parameters for MB adsorption onto unmodified clay (UC)

\begin{tabular}{lllllll}
\hline Isotherm & Langmuir & Freundlich & Temkin & Elovich & Flory-Huggins & Fowler-Guggenheim \\
\hline Parameters & $Q_{0}=0.907$ & $K_{\mathrm{F}}=0.411$ & $B=0.014$ & $Q_{\max }=2.79 \times 10^{5}$ & $n=0.027$ & $W=-3414.3$ \\
& $K_{\mathrm{L}}=1.09 \times 10^{7}$ & $1 / n=3.139$ & $A_{\mathrm{T}}=2.61 \times 10^{6}$ & $K_{\mathrm{E}}=4.46 \times 10^{-6}$ & $K_{\mathrm{FH}}=0.158$ & $K_{\mathrm{FG}}=0.162$ \\
$R^{2}$ & 0.871 & 0.986 & 0.872 & 0.933 & 0.985 & 0.996 \\
EABS & 2.493 & 0.788 & 2.485 & 1.730 & 0.562 & 0.265 \\
$\chi^{2}$ & 1.657 & 0.224 & 1.652 & 0.821 & 0.012 & 0.035 \\
ARE & 62.333 & 19.694 & 62.129 & 43.251 & 14.056 & 6.617 \\
\hline
\end{tabular}


Table 4 Nonlinear isotherm model parameters for $\mathrm{MB}$ adsorption onto $\mathrm{Fe}_{3} \mathrm{O}_{4} @ \mathrm{MC}$

\begin{tabular}{lllllll}
\hline Isotherm & Langmuir & Freundlich & Temkin & Elovich & Flory-Huggins & Fowler-Guggenheim \\
\hline Parameters & $Q_{0}=0.610$ & $K_{\mathrm{F}}=0.888$ & $B=1.182$ & $Q_{\max }=2.95 \times 10^{5}$ & $n=0.000$ & $W=-8210.9$ \\
& $K_{\mathrm{L}}=1.09 \times 10^{7}$ & $1 / n=0.934$ & $A_{\mathrm{T}}=2.201$ & $K_{\mathrm{E}}=2.86 \times 10^{-6}$ & $K_{\mathrm{FH}}=0.150$ & $K_{\mathrm{FG}}=0.021$ \\
$R^{2}$ & 0.500 & 0.747 & 0.717 & 0.746 & 0.500 & 0.542 \\
EABS & 1.193 & 0.743 & 0.787 & 0.771 & 1.451 & 1.289 \\
$\chi^{2}$ & 0.804 & 0.240 & 0.278 & 0.252 & 0.109 & 0.726 \\
ARE & 29.833 & 18.596 & 19.685 & 19.279 & 36.274 & 32.222 \\
\hline
\end{tabular}

where $q_{\mathrm{e}}$ is the amount of $\mathrm{MB}$ adsorbed at equilibrium $\left(\mathrm{mg} \mathrm{g}^{-1}\right), C_{\mathrm{e}}$ is the amount of $\mathrm{MB}$ in the aqueous phase at equilibrium $\left(\mathrm{mg} \mathrm{L}^{-1}\right), Q_{0}$ is the theoretical maximum adsorption capacity $\left(\mathrm{mg} \mathrm{g}^{-1}\right)$ and $K_{\mathrm{L}}$ is the Langmuir constant $\left(\mathrm{L} \mathrm{g} \mathrm{g}^{-1}\right)$.

In this study, the Langmuir model afforded a relatively higher coefficient of determination $R^{2}$ for UC than for $\mathrm{Fe}_{3} \mathrm{O}_{4} @ \mathrm{MC}$ with a maximum adsorption capacity of 0.907 and $0.610 \mathrm{mg} \mathrm{g}^{-1}$ for the UC and $\mathrm{Fe}_{3} \mathrm{O}_{4} @ \mathrm{MC}$. However, there was no change in the Langmuir constant $K_{\mathrm{L}}$ value which could not explain the decrease in the predicted adsorption capacity despite the increase in surface area. Additionally, besides the $R^{2}$ values, the error analysis values depict that the Langmuir model poorly modeled the equilibrium data for both clays relative to all the other isotherm models. Previously, Ghosh and Bhattacharyya (2002) described methylene blue adsorption onto chemically and thermally treated kaolin clays by Langmuir model with maximum adsorption capacities ranging from 7.59 to $20.49 \mathrm{mg} \mathrm{g}^{-1}$. However, the initial concentrations used by the authors were more than five orders of magnitude higher than the present work, and the conclusions arrived at by comparing only two isotherms and using linearization method. Similarly, Zhang et al. (2019) reported a Langmuir maximum adsorption capacity of $184.9 \mathrm{mg} \mathrm{g}^{-1}$ for $\mathrm{MB}$ adsorption onto hierarchical structure kaolinite nanospheres with initial MB concentrations up to 80 orders of magnitude higher than the present work. Mukherjee et al. (2015) reported increased Langmuir adsorption capacity for MB uptake by kaolinite in the presence of an electrolyte from 6.93 to $15.60 \mathrm{mg} \mathrm{g}^{-1}$. Noteworthy, the adsorbent dosage was fivefold more than the present study, and the authors are silent on the initial concentrations used. However, adsorption of MB onto kaolinite clay was demonstrated to be a surface adsorption with no evidence of interlayer spacing penetration (Mukherjee et al. 2015). Interestingly, Boukhemkhem and Rida (2017) reported a Langmuir maximum adsorption capacity of 46.94 and $0.86 \mathrm{mg} \mathrm{g}^{-1}$ for MB adsorption onto kaolinite and metakaolin with BET surface area of 14 and $16 \mathrm{~m}^{2} \mathrm{~g}^{-1}$, respectively. The initial $\mathrm{MB}$ concentrations ranged between 30 and $100 \mathrm{mg} \mathrm{L}^{-1}$, at least 20 times higher than the concentrations used in the present study. It is either thermal treatment of kaolinite decreased its adsorption capacity for MB by $98 \%$ or the estimated values are incorrect due to linearization of the isotherms. Recently, Omer et al. (2018) also reported a Langmuir adsorption capacity of $100 \mathrm{mg} \mathrm{g}^{-1}$ for MB uptake onto a natural clay mineral with an initial MB concentration of $25 \mathrm{mg} \mathrm{L}^{-1}$ and using the linearization approach. Similar conditions and approach were reported by Hajjaji and Alami (2009) for a smectite-rich clay. Other authors have reported MB adsorption onto bentonite clay to be governed by the Redlich-Peterson isotherm using the nonlinear regression (Hong et al. 2009). Therefore, this study shows that the Langmuir model is unsuitable for predicting the adsorbent-adsorbent interactions and the relative adsorption capacities of the kaolinite clays for MB uptake at relatively low concentrations.

\section{Freundlich isotherm}

Freundlich (1906) derived an equation that postulated a multilayer adsorption process onto heterogeneous adsorption sites. The Freundlich model is given as:

$q_{\mathrm{e}}=K_{\mathrm{F}} C_{\mathrm{e}}^{1 / n}$

The magnitude of the Freundlich coefficient $n$ is an index of the favorability of the adsorption reaction (Treybal 1981). When $n$ values less than 1 correspond to a poor adsorptive potential. In this study, the $n$ values of 0.319 for UC (Table 4) suggest a poor adsorption potential. Lesser values of $1 / n$ are associated with strong adsorbate-adsorbent bonding (To et al. 2017). The calculated $1 / n$ value (3.139) denotes weaker adsorbate-adsorbent interactions between $\mathrm{MB}$ and the unmodified clay (UC) (Jemutai-Kimosop et al. 2019). According to Saleh (2015), $1 / n$ values above unity, as in adsorption of MB onto $\mathrm{UC}$, imply cooperative adsorption. Contrarily, the $1 / n$ value for the adsorption of $\mathrm{MB}$ onto $\mathrm{Fe}_{3} \mathrm{O}_{4} @ \mathrm{MC}$ was below unity (0.934) indicating strong adsorbate-adsorbent interactions (Mukherjee et al. 2015). This suggests that chemical modification of the clay introduced newer surfaces with a higher affinity for MB molecules. The aforementioned increased affinity is depicted by the increase in the Freundlich parameter $n$, descriptive of 
the favorability of the adsorption reaction, from 0.319 for UC to 1.071 for $\mathrm{Fe}_{3} \mathrm{O}_{4} @ \mathrm{MC}$ (Treybal 1981). This is further supported by the doubling of the Freundlich constant, $K_{\mathrm{F}}$, value. This implicitly suggests an increase in adsorption, contrary to the predictions from the Langmuir model. Ghosh and Bhattacharyya (2002) described similar findings for MB adsorption onto kaolinite clays at high concentrations with Freundlich exponential factor, $n$, values ranging between 0.047 and 0.151 , corresponding to poor adsorption potential (Treybal 1981). In contrast, Boukhemkhem and Rida (2017) reported good adsorption potential $(n=4.17)$ for MB uptake by raw Algerian kaolin. The Freundlich model, based on error analysis, best described the adsorption of MB onto $\mathrm{Fe}_{3} \mathrm{O}_{4} @ \mathrm{MC}$ relative to the other isotherm models implying multilayer adsorption onto a heterogeneous surface. Similar observations are reported for adsorption of MB onto kaolinite clays at high concentrations.

\section{Temkin isotherm}

Temkin isotherm model (Temkin and Pyzhev 1940) incorporates the effects of adsorbate-adsorbate interactions on the adsorption process. The Temkin isotherm is valid only for an intermediate range of ion concentrations (Shahbeig et al. 2013).

$q_{\mathrm{e}}=B_{\mathrm{T}}\left(A_{\mathrm{T}} C_{\mathrm{e}}\right)$

$B_{\mathrm{T}}=\frac{R T}{b_{\mathrm{T}}}$

In the literature, typical adsorption energies, $\left(B_{\mathrm{T}} \ln \left(A_{\mathrm{T}}\right)\right)$, in the range of $8-16 \mathrm{~kJ} \mathrm{~mol}^{-1}$, are associated with chemisorption as well $\mathrm{asb}_{\mathrm{T}}$ values higher than $80 \mathrm{~kJ} \mathrm{~mol}^{-1}$ (Rahangdale and Kumar 2018). From Table 3, the calculated value of $B_{\mathrm{T}} \ln \left(A_{\mathrm{T}}\right)$ was $0.207 \mathrm{~kJ} \mathrm{~mol}^{-1}$ and a corresponding $b_{\mathrm{T}}$ value of $176.97 \mathrm{~kJ} \mathrm{~mol}^{-1}$. This results in a contradiction, for the $B_{\mathrm{T}} \ln \left(A_{\mathrm{T}}\right)$ value that suggests physical interaction between $\mathrm{MB}$ and $\mathrm{UC}$, while the $b_{\mathrm{T}}$ value corresponds to a chemisorption process. This implies that the Temkin model poorly predicts the adsorption of MB onto UC and this is corroborated by the error function analysis. On the other hands, the error analysis values depict that the Temkin model favorably described the adsorption of MB onto $\mathrm{Fe}_{3} \mathrm{O}_{4} @ \mathrm{MC}$. Here, both the $B_{\mathrm{T}} \ln \left(A_{\mathrm{T}}\right)\left(0.932 \mathrm{~kJ} \mathrm{~mol}^{-1}\right)$ and the $b_{\mathrm{T}}$ values $\left(2.096 \mathrm{~kJ} \mathrm{~mol}^{-1}\right)$ correspond to a physisorption interaction between $\mathrm{MB}$ and $\mathrm{Fe}_{3} \mathrm{O}_{4} @ \mathrm{MC}$. Additionally, the positive $b_{\mathrm{T}}$ value implies that the adsorption process of $\mathrm{MB}$ onto $\mathrm{Fe}_{3} \mathrm{O}_{4} @ \mathrm{MC}$ is exothermic (Miraboutalebi et al. 2017). In contrast, Boukhemkhem and Rida (2017) as well as Ghosh and Bhattacharyya (2002) reported the adsorption of MB onto raw kaolinite clay to be an endothermic reaction. These contradicting outcomes indicate either the dependence of the thermodynamics of adsorption reactions on initial adsorbate concentrations or discrepancies in determination of thermodynamic functions induced by using different adsorption isotherms and equilibrium constants (Tran et al. 2017).

\section{Flory-Huggins isotherm}

Flory-Huggins isotherm model (Horsfall and Spiff 2005) is dependent on the degree of the adsorbent surface coverage characteristics and can be used to predict the thermodynamic feasibility of adsorption reaction. The Flory-Huggins isotherm model is represented by the relation:

$\frac{\theta}{C_{\mathrm{o}}}=K_{\mathrm{FH}}(1-\theta)^{n_{\mathrm{FH}}}$

$\theta=1-\frac{C_{\mathrm{e}}}{C_{\mathrm{o}}}$

where $K_{\mathrm{FH}}$ is the Flory-Huggins' constant $\left[\mathrm{L} \mathrm{mg}^{-1}\right]$. The $n_{\mathrm{FH}}$ parameter represents the number of adsorbate ions occupying sorption sites. Further, the equilibrium constant, $K_{\mathrm{FH}}$, can be used to inspect the spontaneity of the reaction by calculating Gibbs free energy using the relation (Vijayaraghavan et al. 2006):

$\Delta G=-R T \ln K_{\mathrm{FH}}$

The calculated $n_{\mathrm{FH}}$ in this study (Table 4) implies that no molecule was bound on any adsorption site on the $\mathrm{Fe}_{3} \mathrm{O}_{4} @$ $\mathrm{MC}$ adsorbent. This was impractical and bore no physical meaning. This indicates that the Flowry-Huggins could not predict the adsorption of $\mathrm{MB}$ onto $\mathrm{Fe}_{3} \mathrm{O}_{4} @ \mathrm{MC}$ and was rejected. This conclusion is further supported by the error function analysis values that showed that the model poorly fitted the equilibrium data for $\mathrm{Fe}_{3} \mathrm{O}_{4} @ \mathrm{MC}$ relative to all the other isotherms. In contrast, the error function values denote that the Flowry-Huggins isotherm favorably described the adsorption of MB onto the unmodified clay (UC). The calculated Gibbs free energy $(\Delta G)$ from the Flory-Huggins equilibrium constant $\left(K_{\mathrm{FH}}\right)$ was $-4.521 \mathrm{~kJ} \mathrm{~mol}^{-1}$ at $298 \mathrm{~K}$. The negative $\Delta G$ value is a testament that the adsorption of $\mathrm{MB}$ onto UC and by extension $\mathrm{Fe}_{3} \mathrm{O}_{4} @ \mathrm{MC}$ is thermodynamically spontaneous and affirms the feasibility of the process. Adsorption of MB onto kaolinite at higher concentrations is reported to be spontaneous (Ghosh and Bhattacharyya 2002; Boukhemkhem and Rida 2017) and can therefore be affirmed to be spontaneous at all ranges. Furthermore, the magnitude of the $\Delta G$ value, below $20 \mathrm{~kJ} \mathrm{~mol}^{-1}$, calculated from $K_{\mathrm{FH}}$ in this study also suggests that $\mathrm{MB}$ adsorption onto $\mathrm{UC}$ and $\mathrm{Fe}_{3} \mathrm{O}_{4} @ \mathrm{MC}$ is a physisorption process (Almeida 
et al. 2009). This is an agreement with the conclusions from the Temkin isotherm. Similar conclusions though with higher values than the present work $\left(\Delta G \sim 15 \mathrm{~kJ} \mathrm{~mol}^{-1}\right)$ were previously reported despite using the distribution coefficient $\left(K_{\mathrm{d}}\right)$ to derive the thermodynamic functions (Ghosh and Bhattacharyya 2002). However, Boukhemkhem and Rida (2017) reported $\Delta G$ values of $75 \mathrm{~kJ} \mathrm{~mol}^{-1}$ and above using $K_{\mathrm{d}}$ implying chemisorption mechanism, while Almeida et al. (2009) described a physisorption controlled adsorption of MB onto montmorillonite clay using the Langmuir constant $\left(K_{\mathrm{L}}\right)$ to determine $\Delta G$. These variances or possible discrepancies in description of adsorption mechanisms may be overcome by characterization of the dye-laden adsorbents and use of DFT theory rather than from a purely thermodynamics standpoint.

\section{The Fowler-Guggenheim isotherm}

The Fowler-Guggenheim equation (Fowler and Guggenheim 1939) represents the simplest isotherm model developed that factors in the lateral interaction of the adsorbates. The Fowler-Guggenheim equation is given as:

$C_{\mathrm{e}}=\frac{\theta_{\mathrm{FG}}}{K_{\mathrm{FG}}\left(1-\theta_{\mathrm{FG}}\right)} \exp \left(\frac{2 \theta_{\mathrm{FG}} W}{R T}\right)$

where $K_{\mathrm{FG}}$ is the Fowler-Guggenheim constant $\left(\mathrm{L} \mathrm{mg}^{-1}\right), \theta$ the fractional coverage, $R$ is the gas constant $\left(\mathrm{kJ} \mathrm{mol}^{-1} \mathrm{~K}^{-1}\right)$, $T$ is the temperature (K), and $W$ is the interaction energy between adsorbates $\left(\mathrm{kJ} \mathrm{mol}^{-1}\right)$.

The isotherm postulates linear variation of the heat of adsorption with adsorbate loading. According to the model, positive $W$ denotes attractive interaction between the adsorbed molecules. Contrarily, negative $W$ values denote repulsive interactions between adsorbed molecules. However, $W=0$ implies no interaction between the adsorbed molecules. From Tables 3 and 4, the computed values of $W$ were negative for both UC and $\mathrm{Fe}_{3} \mathrm{O}_{4} @ \mathrm{MC}$ indicating repulsive interaction between the adsorbed $\mathrm{MB}$ and decrease in heat of adsorption with loading. Similar findings were reported for adsorption of MB onto Paliurusspina-christifrutis and seeds (PSCFS) adsorbent (Savran et al. 2017). From the error analysis, the Fowler-Guggenheim isotherm best described the adsorption of MB onto UC relative to all the examined models.

\section{Elovich isotherm}

The Elovich model isotherm (Elovich and Larinov 1962) model postulates that the adsorption sites increase exponentially with loading, denoting a multilayer adsorption mechanism. The Elovich equation is given as:

$$
C_{\mathrm{e}}=\frac{q_{\mathrm{e}}}{q_{\mathrm{mE}} K_{\mathrm{E}} \exp \left(\frac{-q_{\mathrm{e}}}{q_{\mathrm{mE}}}\right)}
$$

where $K_{\mathrm{E}}$ is the Elovich constant $\left(\mathrm{L} \mathrm{mg}^{-1}\right)$, and $q_{\mathrm{mE}}$ is the Elovich maximum adsorption capacity $\left(\mathrm{mg} \mathrm{g}^{-1}\right)$.

The Elovich isotherm constants, $K_{\mathrm{E}}$ and $q_{\mathrm{mE}}$, with the corresponding error function values for the adsorption of $\mathrm{MB}$ onto the UC and $\mathrm{Fe}_{3} \mathrm{O}_{4} @ \mathrm{MC}$ presented in Tables 3 and 4 , respectively. Based on error analysis, the Elovich isotherm better fitted the experimental data than the Langmuir and Temkin equations for both adsorbents. The calculated Elovich maximum adsorption capacity of UC and $\mathrm{Fe}_{3} \mathrm{O}_{4} @ \mathrm{MC}$ for adsorption of MB was $2.79 \times 10^{5}$ and $2.96 \times 10^{5} \mathrm{mg} \mathrm{g}^{-1}$, respectively. This shows that the incorporation of magnetite increased the adsorption capacity by about $5.36 \%$ consistent with the increase in BET surface area and increased affinity as denoted by the Freundlich isotherm constants, $n$ and $K_{\mathrm{F}}$. Attunement to the Elovich model suggests multilayer adsorption consistent with the observations from the Freundlich model. Based on the error functions analysis, the suitability of the adsorption isotherms to account for equilibrium data for MB adsorption onto unmodified clay (UC) was in the order Fowler-Guggenheim $>$ Flory-Huggins $>$ Freundlich $>$ Elovich $>$ Temkin $>$ Langmuir model. On the other hands, the isotherm models fitted the adsorption data for $\mathrm{MB}$ onto $\mathrm{Fe}_{3} \mathrm{O}_{4} @$ $\mathrm{MC}$ in the order Freundlich $>$ Elovich $>$ Temkin $>$ Langmuir $>$ Fowler-Guggenheim $>$ Flory-Huggins model. The observed change in sequences bespeaks of the change in adsorption dynamics after modification. This is attributed to changes in chemical composition, surface morphology and textural characteristics.

\section{Conclusions}

In this work, magnetically separable kaolinite clay composite $\left(\mathrm{Fe}_{3} \mathrm{O}_{4} @ \mathrm{MC}\right)$ was developed and applied as an efficient adsorbent for the uptake of methylene blue (MB) dye from synthetic wastewater at low sorbate concentrations. The incorporation of $\mathrm{Fe}_{3} \mathrm{O}_{4}$ on the kaolinite clay resulted in an increase in the BET surface area, and the prepared $\mathrm{Fe}_{3} \mathrm{O}_{4} @$ $\mathrm{MC}$ had a saturation magnetization be $6.22 \mathrm{emu} \mathrm{g}^{-1}$. The equilibrium data were fitted to six nonlinear two-parameter isotherm models, namely Langmuir, Freundlich, Temkin, Elovich, Fowler-Guggenheim and Flory-Huggins models, and the best-fitting model determined using three error functions, viz. Average relative error (ARE), the sum of absolute errors (EABS) and Chi-square $\left(\chi^{2}\right)$. MB adsorption onto unmodified clay (UC) was best described by the Fowler-Guggenheim isotherm, while adsorption onto $\mathrm{Fe}_{3} \mathrm{O}_{4} @ \mathrm{MC}$ was best explained by the Freundlich model. An 
increase in the BET surface area resulted in a $5.36 \%$ rise in Elovich maximum adsorption capacity from $2.79 \times 10^{5}$ and $2.96 \times 10^{5} \mathrm{mg} \mathrm{g}^{-1}$ for $\mathrm{UC}$ and $\mathrm{Fe}_{3} \mathrm{O}_{4} @ \mathrm{MC}$, respectively. The dye-laden exhausted adsorbent was recovered by magnetic separation. The adsorbent-adsorbate interactions and thermodynamic functions are shown to vary significantly at low concentrations relative to previous studies, and therefore, adsorption capacities should only be compared under similar conditions. $\mathrm{Fe}_{3} \mathrm{O}_{4} @ \mathrm{MC}$ is shown to be an efficient adsorbent for $\mathrm{MB}$ sequestration from contaminated water.

Funding This work was supported by DST/FICCI through the award of the C.V Raman International Fellowship to the first author. The CSIRNML staff is acknowledged for their individual and collective support.

\section{Declaration}

Conflict of interest The authors declare no conflict of interest.

Open Access This article is licensed under a Creative Commons Attribution 4.0 International License, which permits use, sharing, adaptation, distribution and reproduction in any medium or format, as long as you give appropriate credit to the original author(s) and the source, provide a link to the Creative Commons licence, and indicate if changes were made. The images or other third party material in this article are included in the article's Creative Commons licence, unless indicated otherwise in a credit line to the material. If material is not included in the article's Creative Commons licence and your intended use is not permitted by statutory regulation or exceeds the permitted use, you will need to obtain permission directly from the copyright holder. To view a copy of this licence, visit http://creativecommons.org/licenses/by/4.0/.

\section{References}

Adeyemo AA, Adeoye IO, Bello OS (2017) Adsorption of dyes using different types of clay: a review. Appl Water Sci 7(2):543-568

Almeida CAP, Debacher NA, Downs AJ, Cottet L, Mello CAD (2009) Removal of methylene blue from colored effluents by adsorption on montmorillonite clay. J Colloid Interface Sci 332:46-53

Bendaho D, Driss TA, Bassou D (2017) Adsorption of acid dye onto activated Algerian clay. Bull Chem Soc Ethiopia 31(1):51-62

Boukhemkhem A, Rida K (2017) Improvement adsorption capacity of methylene blue onto modified Tamazert kaolin. Adsorpt Sci Technol 35(9-10):753-773

Cottet L, Almeida CAP, Naidek N, Viante MF, Lopes MC, Debacher NA (2014) Adsorption characteristics of montmorillonite clay modified with iron oxide with respect to methylene blue in aqueous media. Appl Clay Sci 95:25-31

Elovich SY, Larinov OG (1962) Theory of adsorption from solutions of non-electrolytes on solid (I) equation adsorption from solutions and the analysis of its simplest form, (II) verification of the equation of adsorption isotherm from solutions. Izv Akad Nauk SSSR Otd Khim Nauk 2:209-216

El-Sharkaway EA, Soliman AY, Al-Amer KM (2007) Comparative study for the removal of methylene blue via adsorption and photocatalytic degradation. J Colloid Interface Sci 310:498-508

Fowler RH, Guggenheim EA (1939) Statistical thermodynamics. Cambridge University Press, London, pp 431-450
Freundlich HMF (1906) Über die adsorption in lösungen. Z Phys Chem 57:385-470

Ghosh D, Bhattacharyya K (2002) Adsorption of methylene blue on kaolinite. Appl Clay Sci 20(2002):295-300

Hajjaji M, Alami A (2009) Influence of operating conditions on methylene blue uptake by a smectite rich clay fraction. Appl Clay Sci 44:127-129

Hong S, Wen C, He J, Gan F, Ho YS (2009) Adsorption thermodynamics of methylene blue onto bentonite. J Hazard Mater 167:630-633

Horsfall M, Spiff AI (2005) Equilibrium sorption study of $\mathrm{Al}^{3+}, \mathrm{Co}^{2+}$, and $\mathrm{Ag}^{2+}$ in aqueous solutions by fluted pumpkin (Telfairia occidentalis HOOK) waste biomass. Acta Chim Slov 52:174-181

Jemutai-Kimosop S, Orata F, Shikuku VO, Okello VA, Getenga ZM (2019) Insights on adsorption of carbamazepine onto iron oxide modified diatomaceous earth: kinetics, isotherms, thermodynamics, and mechanisms. Res Environ. https://doi.org/10.1016/j. envres.2019.108898

Karim AB, Mounir B, Hachkar M, Bakasse M, Yaacoubi A (2017) Adsorption/desorption behavior of cationic dyes on Moroccan clay: equilibrium and mechanism. J Mater Environ Sci 8(3):1082-1096

Langmuir I (1916) The constitution and fundamental properties of solids and liquids. J Am Chem Soc 38:2221-2295

Li Y, Yue QY, Gao BY (2010) Effect of humic acid on the Cr(VI) adsorption onto kaolin. Appl Clay Sci 48:481-484

Louhichi S, Ghorbel A, Chekir H, Trabelsi N, Khemakhem S (2016) Properties of modified crude clay by iron and copper nanoparticles as potential hydrogen sulfide adsorption. Appl Clay Sci 127-128:123-128

Markovska L, Meshko V, Noveski V, Marinovski M (2001) Solid diffusion control of the adsorption of basic dyes onto granular activated carbon and natural zeolite in fixed-bed columns. J Serbian Chem Soc $66: 463-475$

Miraboutalebi SM, Nikouzad SK, Peydayesh M, Allahgholi N, Vafajoo L, McKayc G (2017) Methylene blue adsorption via maize silk powder: kinetic, equilibrium, thermodynamic studies, and residual error analysis. Proc Saf Environ Prot 106:191-202

Mohantry K, Naidu JT, Meikap BC, Biswas MN (2006) Removal of crystal violet from wastewater by activated carbons prepared from rice husk. Ind Eng Chem Res 45:5165-5171

Mukherjee K, Kedia A, Jagajjanani K, Dhir S, Paria S (2015) Adsorption enhancement of methylene blue dye at kaolinite clay-water interface influenced by electrolyte solutions. RSC Adv 5:30654

Ogugbue CJ, Sawidis T (2011) Bioremediation and detoxification of synthetic wastewater containing triarylmethane dyes by Aeromonas hydrophila isolated from industrial effluent. Biotechnol Res Int 2011:1-11. https://doi.org/10.4061/2011/967925

Omer SO, Hussein MA, Hussein BHM, Mgaidi A (2018) Adsorption thermodynamics of cationic dyes (methylene blue and crystal violet) to a natural clay mineral from aqueous solution between 293.15 and 323.15 K. Arab J Chem 11:615-623

Otieno S, Kengara FO, Kemmegne-Mbouguen JC, Langmic HW, Kowenje CBO, Mokaya R (2019) The effects of metakaolinization and fused-metakaolinization on zeolites synthesized from quartz rich natural clays. Microporous Mesoporous Mater 290:109668

Ozer D, Dursun G, Ozer A (2007) Methylene blue adsorption from aqueous solution by dehydrated peanut hull. J Hazard Mater 144:171-179

Rahangdale D, Kumar A (2018) Chitosan as a substrate for simultaneous surface imprinting of salicylic acid and cadmium. Carbohydr Polym 202:334-344

Saleh TA (2015) Isotherm, kinetic, and thermodynamics studies on $\mathrm{Hg}(\mathrm{II})$ adsorption from aqueous solution by silica-multiwall carbon nanotubes. Environ Sci Pollut Res 22:16721-16731

Savran A, Selçuk N, Kubilay Ş, Kul A (2017) Adsorption isotherm models for dye removal by Paliurusspina-christi Mill. Frutis and 
seeds in a single component system. J Environ Sci Toxicol Food Technol 11:18-30

Shah KH, Ali S, Shah F, Waseem M, Ismail B, Khan RA, Khan AM, Khan AR (2018) Magnetic oxide nanoparticles $\left(\mathrm{Fe}_{3} \mathrm{O}_{4}\right)$ impregnated bentonite clay as a potential adsorbent for $\mathrm{Cr}(\mathrm{III})$ adsorption. Mater Res Express 5:096102

Shahbeig H, Bagheri N, Ghorbanian SA, Hallajisani A, Poorkarimi S (2013) A new adsorption isotherm model of aqueous solutions on granular activated carbon. World J Modell Simul 9(4):243-254

Shikuku VO, Kowenje CO, Kengara F (2018) Errors in parameters estimation using linearized adsorption isotherms: sulfadimethoxine adsorption onto kaolinite clay. Chem Sci Int J 23:1-6

Shikuku VO, Achieng' GO, Kowenje CO (2019) Removal of dyes from wastewater by adsorption onto low-cost adsorbents. In: Wani KA, Jangid NK (eds) Impact of textile dyes on public health and the environment. IGI Global Publication, Hershey, pp 239-257. https://doi.org/10.4018/978-1-7998-0311-9.ch011

Temkin MI, Pyzhev V (1940) Kinetics of ammonia synthesis on promoted iron catalyst. Acta Phys Chim USSR 12:327-356

To MH, Hadi P, Hui CW, Lin CS, McKay G (2017) Mechanistic study of atenolol, acebutolol and sulfamethoxazole adsorption on waste biomass-derived activated carbon. J Mol Liq 241:386-398

Tran N, You S, Hosseini-Bandegharaei A, Chao H (2017) Mistakes and inconsistencies regarding adsorption of contaminants from aqueous solutions: a critical review. Water Res 120:88-116
Treybal RE (1981) Mass-transfer operations, 3rd ed., McGraw-Hill. Using tree fern as a biosorbent. Process Biochem 40:119-124

Vijayaraghavan K, Padmesh TVN, Palanivelu K, Velan M (2006) Biosorption of nickel(II) ions onto Sargassum wightii: application of two-parameter and three-parameter isotherm models. $\mathrm{J}$ Hazard Mater B 133:304-308

Yasemin B, Haluk A (2006) A kinetics and thermodynamics study of methylene blue adsorption on wheat shells. Desalination 194:259-267

Zhang Q, Zhang Y, Chen J, Liu Q (2019) Hierarchical structure kaolinite nanospheres with remarkably enhanced adsorption properties for methylene blue. Nanoscale Res Lett 14:104. https://doi.org/10. 1186/s11671-019-2934-x

Zheng L, Yang Y, Meng P, Peng D (2019) Absorption of cadmium(II) via sulfur-chelating based cellulose: characterization, isotherm models and their error analysis. Carbohydr Polym 209:38-50

Zou C, Liang J, Jiang W, Guan Y, Zhang Y (2018) Adsorption behavior of magnetic bentonite for removing $\mathrm{Hg}$ (II) from aqueous solutions. RSC Adv 8:27587-27595

Publisher's Note Springer Nature remains neutral with regard to jurisdictional claims in published maps and institutional affiliations. 